\section{References}

${ }^{1}$ De Ponti C, Mauri F, Ciliberto GR, Caru B. Comparative effects of nifedipine, verapamil, isosorbide dinitrate and propranolol on exercise induced angina pectoris. Eur 7 Cardiol 1979;10:47-58.

2 Livesley B, Catley PF, Campbell RC, Oram S. Double-blind evaluation of verapamil, propranolol, and isosorbide dinitrate against a placebo in the treatment of angina pectoris. $\mathrm{Br} \mathrm{Med} \mathcal{F} 1973 ; \mathrm{i}: 375-8$.

${ }^{3}$ Parodi O, Maseri A, Simonetti I. Management of unstable angina at rest by verapamil: a double-blind cross-over study in coronary care unit. Br Heart 7 1979;41:167-74.

4 Fleckenstein A. Specific inhibitors and promoters of calcium action in the excitation contraction coupling of heart muscle and their role in the prevention or production of myocardial lesions. In: Harris P, Opie L, eds. Calcium and the heart. London: Academic Press, 1970: 135-86.

5 Ekelund LG, Oro L. Antianginal efficiency of nifedipine with and without a beta blocker studied with exercise test. A double-blind randomised subacute study. Clin Cardiol 1979;2:203-11.

- Muller JE, Gunther SJ. Nifedipine therapy for Prinzmetal's angina. Circulation 1979;57:137-9.

${ }^{7}$ Rowland E, Evans T, Krikler D. Effect of nifedipine on atrioventricular conduction as compared with verapamil. Br Heart $\mathcal{f} 1979$;42:124-7.

${ }^{8}$ Fox K, Selwyn A, Shillingford JP. A method for praecordial surface mapping of the exercise electrocardiogram. Br Heart $71978 ; 40: 1339-43$.
9 Katz LN, Feinberg $H$. The relation of cardiac effort to myocardial oxygen consumption and coronary flow. Circ Res 1958;6:656-69.

${ }^{10}$ Fox KM, Selwyn A, Oakley D, Shillingford JP. Relation between the precordial projection of ST segment changes after exercise and coronary angiographic findings. Am $\mathcal{f}$ Cardiol 1979;44:1068-75.

11 Hillis LD, Braunwald E. Coronary artery spasm. New Engl f Med 1978; 299:695-702.

12 Vater W. Myocardial oxygen consumption under the influence of nifedipine (Adalat) in the anesthetized dog. In : Lochner W, Braasch W, Kroneberg $\mathrm{G}$, eds. Second international nifedipine (Adalat) symposium. New York: Springer-Verlag, 1975:77-81.

${ }^{13}$ Schang SJ, Pepine CJ. Transient asymptomatic ST segment depression during daily activity. Am $\mathcal{F}$ Cardiol $1977 ; 39: 396-402$.

14 Selwyn AP, Fox K, Eves M, Oakley D, Dargie HJ, Shillingford J. Myocardial ischaemia in patients with frequent angina pectoris. $\mathrm{Br} \mathrm{Med} \mathcal{F}$ 1978 ;ii:1594-6.

${ }^{15}$ Maseri A, Silva S, de Nes M, L'Abbate A, Chierchia S. "Variant angina": one aspect of a continuous spectrum of vasospastic myocardial ischemia. Am f Cardiol 1978;42:1019-35.

16 Balasubramanian V, Raftery EB, Stott FD. Myocardial ischaemia in patients with frequent angina pectoris. $B r \operatorname{Med} \mathcal{f} 1979 ; \mathrm{i}: 198$.

(Accepted 16 May 1980)

\title{
Outbreak of tuberculosis after minimal exposure to infection
}

\author{
V R RAO， R F JOANES，PAULA KILBANE， N S GALBRAITH
}

\section{Summary and conclusions}

The identification of a case of respiratory tuberculosis in a swimming-baths attendant whose sputum was smear positive was followed by intensive contact tracing of children aged 8-11 years who had visited the baths. An outbreak was discovered that otherwise might not have been detected. Out of 3764 children, $108(2.9 \%)$ had evidence of infection: there were 16 cases of tuberculosis, of which 11 were symptomless but showed lesions on chest radiography, and a further 92 with tine test grade 3 or 4 without clinical or radiological signs. The contact of these children with the index case was apparently minimal.

Early detection, isolation, and treatment of infectious cases of respiratory tuberculosis and vigorous contact tracing should be given more priority in tuberculosis control.

\section{Introduction}

An outbreak of tuberculosis in children aged 8-11 years occurred between January and March 1979 in Sandwell, West Midlands, a metropolitan district with a matching single-district area health authority, situated immediately north-west of Birmingham. It is a heavy industrial district with a declining population, which at the 1971 Census numbered 328100 , over $3 \%$ of whom were Asian immigrants. Infant and perinatal

\footnotetext{
Sandwell Area Health Authority, West Bromwich, West Midlands B70 9OD

V R RAO, MFCM, DPH, specialist in community medicine (environmental health)

R F JOANES, MFCM, DPH, specialist in community medicine (child health)

Communicable Disease Surveillance Centre, London NW9 5EQ PAULA KILBANE, MFCM, senior registrar N S GALBRAITH, MRCP, FFCM, director
}

mortality rates exceeded the national average. The notification rate of tuberculosis in 1977 was over twice the national rate, which possibly reflected the problem of tuberculosis in innercity immigrants experienced elsewhere in Britain. ${ }^{2}$ This part of the West Midlands was well provided with tuberculosis services; there were three chest clinics, with attached healthvisiting staff, each of which served part of the Sandwell area.

The outbreak was detected by intensive contact tracing of children who had used a swimming pool supervised by a man with the disease.

\section{Index case}

The index case was a 25-year-old United-Kingdom born white man who had worked for Sandwell Borough Council as a baths attendant since November 1976. A pre-employment chest radiograph had been normal. He began to feel unwell in the spring of 1978, developed a cough in the summer, which he attributed to his heavy smoking (40 cigarettes a day) and in the autumn became breathless on exertion, tired, and lost his appetite. He had a haemoptysis at work in February 1979 and was referred to the local chest clinic. Radiography showed extensive bilateral tuberculosis, and a sputum-smear test was positive. He was admitted to hospital for isolation and treatment. He recalled that in August 1978 he had undergone chest radiography after a minor motorbike accident; the radiograph showed a small right middle-lobe cavity, which had escaped detection at the time. The source of his infection was not discovered.

His work as an attendant at a local heated indoor swimming pool entailed keeping the surrounds of the pool clean and free of obstruction and supervising bathers. Supervision was carried out sitting on a $6 \mathrm{ft}$ $(1.8 \mathrm{~m})$ high platform in the centre of one side of the pool, from which bathers could readily be observed in any part of the pool. He never instructed in swimming or life saving and apparently had no close contact with bathers.

\section{Outbreak}

Immediately the index case was detected his close home and work contacts were examined. Out of 13 adults, one (his girlfriend) had a small apical shadow, but the remainder were normal. One child, the 


\begin{tabular}{|c|c|c|}
\hline Type of contact & No of subjects & Results of investigations \\
\hline $\begin{array}{l}\text { Home contacts and baths staff } \\
\text { General public who visited bat }\end{array}$ & 13 adults; 1 child & 1 apical tuberculosis on radiography; 1 primary tuberculosis on radiography \\
\hline $\begin{array}{l}1979 \\
\text { Schoolchildren aged 8-11 who visited baths between September } 1978 \\
\text { and February } 1979\end{array}$ & $\begin{array}{l}303 \text { adults } \\
3764 \text { children }\end{array}$ & $\begin{array}{l}\text { All radiologically normal on mass miniature radiography } \\
5 \text { clinical tuberculosis; } 10 \text { lesions on radiography; } 92 \text { tine grade } 3 \text { or } 4 \\
\text { without symptoms or signs }\end{array}$ \\
\hline
\end{tabular}

girlfriend's 8-year-old sister, had a strongly positive tuberculin test (tine grade 4) and a primary lesion in the chest radiograph (table I).

Because the index case had been ill for about nine months before detection and had extensive bilateral cavitating disease it was assumed that he had been infectious from about September 1978. Adults who had visited the swimming pool between this date and February 1979 were offered mass miniature radiography: 303 accepted, and all were negative (table I).

Between September 1978 and February 1979, 3764 schoolchildren aged 8-11 years had visited the swimming pool with their classes from 22 local primary schools. The visits, of half to three-quarters of an hour, were made regularly once a week under the supervision of the class teacher, and the children were transported to and from the swimming pool by a special bus. There was one driver only; he was well and had a normal chest radiograph. On investigation one of the children had already been notified as tuberculosis with erythema nodosum with onset in early January 1979. Subsequently two children with pleural effusions, one with tuberculous meningitis, and one with miliary tuberculosis were reported in different parts of the borough, all of whom had visited the pool with their schools.

It was decided to tuberculin test all 3764 children; parental consents were obtained in writing, and the tests were carried out over three weeks beginning on 12 March 1979 . Altogether $184(4.9 \%)$ of the children were tine-test positive, $108(2.9 \%)$ of whom were strongly positive grade 3 or 4 . These 108 children included the five clinical cases above and a further 10 who had lesions in chest radiographs, and the sister of the girlfriend of the index case (table I). All children with strongly positive tests were given prophylaxis with isoniazid $100 \mathrm{mg}$ twice daily and ethambutol $200 \mathrm{mg}$ twice daily for three months.

A tuberculin survey in four of the 22 schools confirmed the association of strongly positive tuberculin tests (tine grades 3 and 4) with swimming (table II). Out of 1025 children in the four schools, 681

TABLE II-Tuberculin survey in four primary schools (children aged 8-11)

\begin{tabular}{lcrc}
\hline \multirow{2}{*}{$\begin{array}{c}\text { Tine } \\
\text { test } \\
\text { grade }\end{array}$} & \multicolumn{3}{c}{ No $(\%)$ of children tested } \\
\cline { 2 - 4 } & Swimmers & Non-swimmers & Total \\
\hline $3 \& 4$ & $34(5)$ & $5(1)$ & 39 \\
$1 \& 2$ & $23(3)$ & $12(3)$ & 35 \\
Negative & $624(92)$ & $327(95)$ & 951 \\
\hline Total & $681(100)$ & $344(100)$ & 1025 \\
\hline
\end{tabular}

$\chi^{2}$ with $2 \mathrm{df}=7 \cdot 8 ; \mathrm{p}<0.025$.

had visited the swimming baths between September 1978 and February 1979 and 344 had not. Among the swimmers $34(5 \%)$ had grade 3 or 4 tine tests, and among the non-swimmers $5(1 \%)$ had grade 3 or 4 tests; this difference was significant $\left(\chi^{2}=6.9 ; p<0.01\right)$.

The home addresses of 163 of the 184 children with positive tine tests were analysed and showed no relation between the grade of the tests and the distances of their homes from the baths (table III). This suggested that personal visits that children living near the baths may have made during holidays or out of school hours was not important.

\section{Swimming baths}

The swimming bath was a well kept municipal baths built during the 1930s with slipper baths and changing rooms on either side of an entrance hall and a main swimming pool $40 \times 10$ yd $(36.5 \times 9.0 \mathrm{~m})$. This pool was ventilated by intake fans at the deep end of the building set about $10 \mathrm{ft}(3 \mathrm{~m})$ high in the wall and extractor fans at the shallow end set at about $20 \mathrm{ft}$ above the pool; thus the airflow was from the deep end to the shallow end.

The contact of the index case with the infected children seems to have been minimal. The platform from which he supervised the bathers was about $20 \mathrm{yd}(18 \mathrm{~m})$ down one side of the pool and between 10 and $20 \mathrm{yd}$ from the children, most of whom used the shallow end for swimming under the guidance of their teacher. Possibly the airflow in the baths caused droplet nuclei from the index case to fall on the shallow end of the pool. If so the children must have been infected during the $20-30$ minutes that they spent in the pool in 10-15 visits

TABLE III-Tine tests and distances of homes from baths

\begin{tabular}{|c|c|c|c|c|c|}
\hline \multirow{3}{*}{$\begin{array}{l}\text { Tine } \\
\text { test } \\
\text { grade }\end{array}$} & \multicolumn{5}{|c|}{ No $(\%)$ of children tested } \\
\hline & \multicolumn{4}{|c|}{ Distance from swimming pool in miles* } & \multirow{2}{*}{ Total } \\
\hline & $<1$ & $1-1 \frac{1}{2}$ & 2 & $>2$ & \\
\hline $\begin{array}{l}1 \& 2 \\
3 \& 4\end{array}$ & $\begin{array}{l}32(47) \\
47(49)\end{array}$ & $\begin{array}{l}18(26) \\
25(26)\end{array}$ & $\begin{array}{r}-7(10) \\
12(13)\end{array}$ & $11(16)$ & $\begin{array}{l}68(100) \\
95(100)\end{array}$ \\
\hline Total & $79(48)$ & $43(26)$ & $19(12)$ & $22(13)$ & $163(100)$ \\
\hline
\end{tabular}

*One mile is approximately $1.6 \mathrm{~km}$.

made by them during the period the index case was likely to have been infectious. There was a possibility of contact in a locker room that the children entered briefly to leave their clothes before entering the swimming pool. The index case occasionally sat on a linen basket at the end of this room when he was particularly tired and not engaged in supervisory duties.

\section{Discussion}

This outbreak illustrates how readily tuberculosis can spread from highly infectious sputum-smear-positive cases of respiratory disease to susceptible contacts with minimal exposure. Indeed, tuberculosis is probably mainly spread by a small number of such highly infectious people. ${ }^{3}$

On detecting a case of respiratory tuberculosis with smearpositive sputum the patient should be isolated in hospital and appropriate chemotherapy begun as soon as possible. Though patients probably lose their infectivity within two weeks, viable tubercle bacilli may persist for longer. ${ }^{4}$ Isolation in hospital for two to four weeks is therefore desirable and is valuable in establishing the patient on treatment under supervision, thus reducing the risk of non-compliance.

The clinician making the diagnosis should report the case immediately to his community physician colleagues so that urgent investigation of contacts at work and at home can begin.

The present outbreak would probably have gone undetected without the investigation of children attending the swimming pool because it is unlikely that this link between the overt clinical cases would have otherwise been discovered. We therefore suggest that when investigating new cases of tuberculosis in children more emphasis should be placed on trying to find epidemiological links between them. They are likely to have acquired the infection from a case of "open" respiratory tuberculosis with a smear-positive sputum test, and the possibility that several children might have derived the disease from the same source should not be ignored. As tuberculosis declines in the community the younger members who have not been protected by BCG vaccination will have low immunity similar to that found in communities that have not experienced tuber- 
culosis. $^{5}$ In these circumstances small outbreaks around isolated infectious cases are to be expected and should be sought with diligence.

\section{References}

1 Springett VH. Tuberculosis in immigrants in Birmingham 1970-72. $B r f$ Prev Soc Med 1973;27:242-6.
2 Joint Tuberculosis Committee Memorandum. Tuberculosis among immigrants in Britain. Br Med $\mathcal{F} 1978 ; \mathrm{i}: 1038-40$.

${ }^{3}$ Pagel W, Simmonds FAH, Macdonald N, Nassau E. Pulmonary tuberculosis. London: Oxford University Press, 1964:476.

${ }^{4}$ Rouillon A, Perdrizet S, Parrot R. Transmission of tubercle bacilli: the effects of chemotherapy. Tubercle 1976;57:275-99.

5 Heaf F, Lloyd Rusby N. Recent advances in respiratory tuberculosis. 6th ed. London: Churchill, 1968:7.

\title{
Effects of pseudoephedrine and triprolidine, alone and in combination, on symptoms of the common cold
}

\author{
C E BYE, J COOPER, D W EMPEY, A S E FOWLE, D T D HUGHES, E LETLEY, J O’GRADY
}

\section{Summary and conclusions}

A total of 466 healthy adults from four different regions of England entered a double-blind, randomised trial to test the effectiveness of an antihistamine (triprolidine) and a decongestant (pseudoephedrine), alone or in combination, in relieving symptoms of the common cold. During the study 199 subjects reported a total of 243 colds. Subjects recorded the severity of 12 symptoms during treatment and noted separately the severity of a further seven symptoms that represented unwanted effects of treatment or served as an index of suggestibility. They were then asked about their overall improvement in symptoms during treatment and whether they thought they had taken placebo.

Sneezing, nasal obstruction, and overall response to treatment were significantly improved $(p<0.01)$ with pseudoephedrine or pseudoephedrine and triprolidine compared with placebo.

\section{Introduction}

The common cold cannot yet be prevented so doctors and patients have to be satisfied with whatever they think lessens the misery of its symptoms. The popular supposition that concurrent treatment with an antihistamine and a decongestant provides some relief of symptoms is reflected by the vast consumption of proprietary formulations of this kind. Yet wellconducted studies have not shown any benefit from such treatment, at least with antihistamines. ${ }^{1}$ We therefore examined the effects of a decongestant and antihistamine combination in a study using only subjective criteria. We argued that although

Clinical Research Division, Wellcome Research Laboratories, Beckenham, Kent BR3 3BS

C E BYE, MA, statistician

A S E FOWLE, MD, FRCP, head of department of clinical pharmacology

E LETLEY, PHD, MRCP, clinical pharmacologist

J O'GRADY, MB, MRCP, clinical pharmacologist

Wellcome Medical Division, Wellcome Foundation Ltd, Crewe, Cheshire CW1 1 UB

J COOPER, $M B$, head of scientific services division

Department of Chest Medicine, the London Hospital, London E1 1BB D W EMPEY, MB, MRCP, consultant physician

D T D HUGHES, BM, FRCP, consultant physician the range of symptoms of the common cold was wide, the symptoms in any one person were probably fairly constant, so that each person might thus be regarded as an expert on his or her own symptoms. Their opinions on the effects of a treatment on wellbeing should be conclusive even when the components of that feeling cannot be fully analysed and measured. We attempted to see whether symptoms of the common cold were influenced differently by treatment with an antihistamine (triprolidine) and a decongestant (pseudoephedrine) separately and in combination, or by a dummy treatment.

\section{Subjects and methods}

A panel of 466 healthy volunteers was enrolled before the trial period from the staff of the Wellcome Foundation in four different regions in England. From 1 October 1976 to 31 March 1977, 199 people had one cold, 36 had two colds, seven had three colds, and one had four colds, making a total of 243 colds. After developing a cold all subjects were interviewed by a nursing sister, who admitted them to the study subject to compliance with entry criteria designed to ensure regional conformity and to exclude volunteers taking medicines that could interfere with the study. An interview questionnaire was later used to check for homogeneity within the treatment groups for age, sex, usual number of colds each winter, absence of allergic disorders, smoking habits, duration of symptoms, and signs of fever.

Drugs were allocated from separate randomisation lists for men and women aged below and above 40 years and at each centre (16 lists in all). Balance in numbers was arranged after every eighth person in each list. The treatments administered were as follows: placebo, 63 courses; pseudoephedrine hydrochloride $60 \mathrm{mg}, 63$ courses; triprolidine hydrochloride $2.5 \mathrm{mg}, 61$ courses; and pseudoephedrine $60 \mathrm{mg}$ and triprolidine $2.5 \mathrm{mg}$, 56 courses. Drugs were issued to patients in coded bottles containing 20 tablets with instructions to take one tablet three times daily for as long as they thought necessary. All tablets were identical in appearance. All were specially made and differed in appearance from marketed preparations.

Volunteers had to mark for severity using a four-point scale 12 symptoms relating to the common cold on a daily diary card. The 12 symptoms were those most often mentioned in a preliminary poll taken in two of the four regions. The volunteers also had to mark for severity in a separate daily diary seven symptoms, four of which were possible unwanted effects of treatment (palpitations, sleeplessness, drowsiness, and dry mouth) and three unlikely effects that provided an index of suggestibility. Finally, on the eighth to tenth day they were asked by a nursing sister standardised questions about their overall impression of improvement in symptoms while taking tablets and also specifically, "Do you think the trial tablets you took were the placebo ?"

Symptom scores and other numerical data were analysed by the $\chi^{2}$ test. The significance level was $\mathrm{p}<0.05$ except when comparison of the four treatments showed a significant difference, when individual comparisons in pairs were made with the significance 